\title{
Acute coronary syndromes: We must improve diagnostic efficiency in the emergency department
}

\author{
Jim Christenson, MD
}

\begin{abstract}
RÉSUMÉ : Chaque année, 100000 Canadiens sont hospitalisés pour des syndromes coronariens aigus (SCA) (infarctus aigu du myocarde et angine instable); un aussi grand nombre de patients sont hospitalisés pour que soit finalement «écarté» le diagnostic de SCA. Le diagnostic de SCA doit être rapide et exact afin de réduire le taux de mortalité et de prévenir la progression de l'angine instable vers un infarctus du myocarde. En même temps, on doit limiter les coûts inutiles liés au traitement de ces patients. Malheureusement, aucune épreuve ou stratégie particulières ne permettent d'identifier de façon définitive tous les patients atteints de SCA. Les unités de douleur thoracique à l'urgence, de plus en plus populaires, permettent de réduire le nombre d'hospitalisations aux unités de soins critiques en appliquant des protocoles diagnostiques intensifs au département d'urgence. Mais ces unités diminuent-elles les coûts ou ne font-elles qu'augmenter la proportion de patients soumis à des épreuves? Plutôt que de soumettre tous les patients au même processus diagnostique, les urgentologues devraient classer les patients selon leur risque parmi l'une des trois catégories suivantes: ceux dont la probabilité de SCA est faible qui nécessitent un minimum d'épreuves à I'urgence; ceux qui présentent des signes évidents de SCA et qui doivent être hospitalisés; et ceux dont la probabilité de SCA est intermédiaire et qui doivent subir différentes épreuves.
\end{abstract}

\section{Introduction}

Almost every shift, emergency physicians agonize over patients who present with chest pain. Every year approximately 100000 patients are hospitalized with acute myocardial infarction (AMI) or unstable angina (acute coronary syndromes $[\mathrm{ACS}]) .{ }^{1}$ Canadian registry data (FASTRAK II) suggest that at least another 100000 patients are admitted with chest pain and subsequently have ACS ruled out. ACS are perhaps the most controversial issue in emergency medicine.

\section{What are acute coronary syndromes?}

ACS include ST-elevation AMI, non-ST-elevation AMI and unstable angina. These 3 diagnoses share similar pathophysiology and have many aspects of treatment in common. The culprit lesion is usually a ruptured athero- sclerotic plaque in a coronary artery. The resultant exposed collagen, now unprotected by intact endothelium, is highly thrombogenic. A monolayer of platelets adheres to the open surface, and nearby platelets are activated to aggregate with each other and form a platelet plug. Soluble fibrinogen is rapidly converted to fibrin in a mesh that solidifies the platelet plug into a clot. Clots are dynamic and in constant flux between mechanisms that accelerate the clotting process and mechanisms that facilitate clot breakdown.

Clot causes obstruction to flow with resultant ischemia. The ischemia can cause transmural necrosis (ST-elevation AMI), partial necrosis (non-ST-elevation AMI) or no necrosis (unstable angina) depending on the duration and degree of occlusion, the amount of myocardium served by the blocked vessel and the extent of collaterals. Physicians should think of ACS as a ruptured plaque with an active clot occluding or threatening to occlude a coronary artery. 


\section{Why is it important to make the diagnosis of acute coronary syndromes in the emergency department?}

Significant short-term mortality exists in all ACS. Generally this mortality is highest for ST-elevation AMI, followed by non-ST-elevation AMI, followed by unstable angina. Unstable angina can progress to non-ST-elevation AMI, which can progress to ST-elevation AMI. Progression to a higher risk group is potentially avoidable; therefore, preventing progression is a primary goal of management. Mortality in each group can be reduced by early appropriate therapy. Although the benefit of rapid treatment is most clearly shown for ST-elevation AMI, it is also logical that early recognition and treatment of unstable angina and non-ST-elevation AMI will limit myocardial necrosis and improve outcomes.

Conversely, although it is important to make a rapid, accurate diagnosis of patients with ACS, every patient without serious illness who is admitted or subjected to a costly diagnostic work-up consumes health care resources that are then unavailable for other important health care needs. Diagnostic efficiency and cost-effectiveness are important. Therefore, in a perfect world, all patients with ACS would be recognized and treated appropriately in the ED, and those without ACS would be sent home or treated for the cause of their symptoms.

\section{Why is it so hard to make a definitive diagnosis?}

There are no tests that alert us to plaque disruption and early clot formation. As a result, no single ED test or combination of tests is sensitive for ACS. Clinical estimates of disease probability are driven mostly by the patient's history and presenting electrocardiogram (ECG); however, atypical symptoms are relatively common, and patients without risk factors still suffer ACS. Electrocardiograms are helpful when positive, but in up to $50 \%$ of patients with ACS the results are normal or non-specific. ${ }^{2-6}$ Serum markers don't rise until 4 to 6 hours after the onset of myocardial necrosis, and they remain normal in patients with unstable angina who have an unstable plaque and are in imminent danger of sudden coronary artery occlusion. Other investigations, including sestamibi nuclide scanning and stress tests, show promise but are frequently unavailable in the ED.

\section{How do we currently decide whether to admit or discharge?}

A patient with chest pain is seen by the emergency physician, who takes a history, orders an ECG and decides, based on his or her accumulated wisdom, hospital resources, hospital pattern of practice, and personality traits, whether the patient should be admitted and, if so, what therapies to initiate. As physicians gain experience they become more sensitive and less specific, discharging fewer patients with AMI but admitting more without ACS. ${ }^{7}$ This pattern is understandable because the physician's primary concern for patient safety drives him or her to use a threshold that is maximally sensitive. However, admission practices vary widely, and in a large Canada/US study of serial cardiac markers, admission rates for patients with chest pain ranged from $49 \%$ to $87 \%{ }^{8}$ It is likely that individual physician disposition decisions are also extremely variable even within a single institution.

\section{What are chest pain units and why are they so popular in the US?}

ACS are lethal, difficult to diagnose and often require observation and serial testing over time. Chest pain units are therefore a logical solution. Many US hospitals have already established such units to address diagnostic uncertainty, ${ }^{9-11}$ and many more units are currently under development. Hospitals and physicians want to limit the risk associated with inappropriate discharges, and patients want to have confidence that the hospital they attend is providing the "best" care.

Chest pain units are designated areas, often within the $\mathrm{ED}$, that have 2 main functions. First, patients who need urgent stabilization or initiation of anti-ischemic therapy are rapidly recognized and treated before being transferred to a critical care unit or catheterization laboratory. Second, patients with undiagnosed or obscure chest pain of possible cardiac origin are held in chest pain units, where they typically undergo an expensive, protocol-driven battery of tests to rule out ACS. Diagnostic protocols, which can take anywhere from 9 to 24 hours to complete, prevent some critical care unit admissions but extend ED lengths of stay.

Diagnostic protocols in chest pain units include combinations of: clinical observation, frequent serum markers, continuous ST-segment monitoring or serial ECGs, echocardiography, nuclide scanning and stress tests. Despite expensive work-ups there is little good evidence that the application of these protocols improves patient outcomes.

\section{Let's not forget about clinical judgement}

Chest pain units help us focus on more efficient methods of ruling out ACS. Unfortunately, they will encourage work- 
ups on more patients - even those with very low clinical likelihood of disease. And although chest pain units are costeffective compared with admitting patients to a critical care unit for 1 to 2 days, increased numbers of patients subjected to intensive investigation could actually increase the overall diagnostic costs for all patients presenting with chest pain.

We should not forget that clinical judgement is a powerful tool. Many experienced emergency physicians rapidly identify low-risk patients from their history, ECG and brief observation. In a large study ${ }^{8}$ of diagnostic serum markers in patients with chest pain, the ED discharge rate by centre was as high as $51 \%$. Of patients discharged after a limited ED evaluation, fewer than $1 \%$ experienced ischemic complications within a week and no deaths occurred due to unrecognized ischemia - strong evidence that physicians can be reasonably specific with their initial assessment. Unfortunately, we don't understand the process that good physicians use in making these assessments, nor has this decision process been scientifically evaluated.

\section{Defining three groups of patients with chest pain}

Patients who present with chest pain (or symptoms consistent with ACS) can be placed in 1 of 3 categories. Each category requires a different diagnostic and therapeutic approach, and each has an urgent research agenda.

Patients in the first (high-risk) group have objective signs of myocardial ischemia, including ST-elevation AMI, STdepression or T-wave inversion signifying unstable angina or non-Q-wave AMI, or elevated serum markers signifying myocardial necrosis (including micro-infarcts or high-risk unstable angina). For this group, ongoing research is aimed at optimal reperfusion strategies, fibrinolytic agents, antiplatelet therapies, thrombin inhibitors and strategies to shorten the time to reperfusion in appropriate patients.

Patients in the second (moderate-risk) group have no objective signs of ischemia, but have a clinical presentation compatible with ACS. These patients should enter a rapid diagnostic track in an actual or "virtual" chest pain unit to determine whether an acute coronary syndrome is the cause of their symptoms. The most efficient and effective diagnostic protocol has yet to be defined and will require further research.

Patients in the third (low-risk) group can be discharged from the ED after a brief assessment and observation period. These patients should not undergo expensive diagnostic tests. The difficult challenge we face is identifying which patients fall into this category.

\section{A clinical prediction rule for low-risk patients?}

Our time-honoured diagnostic approach is to identify patients with disease and let the others fall out. This is particularly difficult when there are no sensitive tests to determine who has disease. Therefore, a promising approach is to reverse our logic and identify patients without disease, much like we use the Ottawa Ankle Rules to identify patients who do not require an X-ray. An ACS prediction rule that would identify low-risk patients based on common clinical criteria would be of great value in helping emergency physicians determine which patients are safe to discharge.

Clinical prediction rules have been developed and tested in emergency medicine in a more rigorous manner than any other specialty. The Ottawa Ankle Rules ${ }^{12}$ tell us which extremity injuries can be managed without radiography, and similar methodology is now being used to help us make more complicated decisions, such as which patients need computed tomography after "minor" head trauma. A practical rule to identify patients with chest pain who can safely be discharged early would have enormous implications. Such a rule would identify a significant portion of the more than 100000 patients admitted each year for negative diagnostic work-up. The daily direct nursing cost of a Canadian critical care unit bed is approximately $\$ 665$ per day, excluding tests, consultations and institutional overhead (costing database, St. Paul's Hospital, Vancouver, 1998 data). If only 25\% of "low-risk" patients could be saved 1 day's stay in hospital, the savings in nursing care alone would approximate $\$ 16625000$ per year, and the true cost savings are likely to be far greater.

\section{Conclusions}

The complicated and difficult diagnostic issues that surround patients who present to the ED with possible ACS can and must be simplified. As emergency physicians we need to objectify our early decisions in patients with chest pain. A clinical tool should be developed to answer the question, Who can be safely discharged after a brief early assessment?

Patients at low risk should be identified as safe for discharge and should not undergo intensive investigation. Patients at moderate risk should undergo a rapid and inexpensive diagnostic protocol. At any time in this diagnostic process, objective evidence of ischemia must be rapidly recognized and urgently treated if we are to provide the best and most cost-effective care to patients presenting with acute coronary syndromes. We must commit ourselves to understanding how we diagnose and dispose of ED patients with ACS. Determining how to do it better is our challenge. 


\section{References}

1. Heart and Stroke Foundation of Canada. Heart disease and stroke in Canada. Ottawa: The Foundation; 1997.

2. Ben-Haim SA, Gil A, Edoute Y. Beat-to-beat morphologic variability of the electrocardiogram for the evaluation of chest pain in the emergency room. Am J Cardiol 1992;70:1139-42.

3. Baxt WG, Skora J. Prospective validation of artificial neural network trained to identify acute myocardial infarction. Lancet 1996;347:12-5.

4. Fesmire FM, Smith EE. Continuous 12-lead electrocardiograph monitoring in the emergency department. Am J Emerg Med 1993;11(1):54-60.

5. Fesmire FM, Percy RF, Bardoner JB, Wharton DR, Calhoun FB. Usefulness of automated serial 12-lead ECG monitoring during the initial emergency department evaluation of patients with chest pain. Ann Emerg Med 1998;31:3-11.

6. Lee HS, Cross SJ, Garthwaite P, Dickie A, Ross I, Walton S, et al. Comparison of the value of novel rapid measurement of myoglobin, creatine kinase, and creatine kinase-MB with the electrocardiogram for the diagnosis of acute myocardial infarction. $\mathrm{Br}$ Heart J 1994;71:311-5.

7. Rusnak RA, Stair TO, Hansen K, Fastow JS. Litigation against the emergency physician: common features in the cases of missed myocardial infarction [see comment]. Ann Emerg Med 1989;18:1029-34. Comment in: Ann Emerg Med 1990;19(9): 1074.

8. Gibler WB, the SMARTT investigators. Does STAT reporting of serial serum markers (CK-MB and myoglobin) aid in early detection and treatment decisions for acute MI? [abstract] J Am Coll Cardiol 1997;29(suppl):186A.

9. Anderson HJ. Hospitals battle heart attacks with new chest pain centers. Hospitals 1991;65:36-7.

10. Zalenski RJ, Rydman RJ. Prevalence, characteristics, and organizational context of emergency department chest pain centers in the United States. Circulation 1996;94:1-50.

11. Graff L, Joseph T, Andelman R, Bahr R, DeHart D, Espinosa J, et al. American College of Emergency Physicians information paper: chest pain units in emergency departments - a report from the Short-Term Observation Services Section. Am J Cardiol 1995;76(14):1036-9.

12. Stiell I, Greenberg G, McKnight R, Nair R, McDowell I, Reardon M. Decision rules for the use of radiography in acute ankle injuries: refinement and prospective validation. JAMA 1993;269:1127-32.

Correspondence to: Dr. Jim Christenson, Department of Emergency Medicine, St. Paul's Hospital, 1081 Burrard St., Vancouver BC V6Z 1Y6; jimchris@unixg.ubc.ca
AN EXCLUSIVE OFFER TO MEMBERS OF THE CANADIAN ASSOCIATION OF EMERGENCY PHYSICIANS

Voluntary Group Term Life Insurance

Units of $\$ 25,000$ to a maximum of $\$ 300,000$

Sample Monthly Premiums: $\$ 200,000$, non-smoker aged 39:

$\begin{array}{ll}\text { Male } & \$ 19.60 \\ \text { Female } & \$ 16.00\end{array}$

Accidental Death \& Dismemberment Insurance Insurance Amount $\quad \$ 100,000 \quad \$ 250,000 \quad \$ 500,000$

Monthly Premium $\$ 2.50 \quad \$ 6.25 \quad \$ 12.50$

Medical Crisis Recovery (Critical IIIness Insurance)

Tax Free Lump Sum benefit paid to insured members who are diagnosed with one of the following:

$\begin{array}{lll}\text { Cancer } & \text { Quadriplegia } & \text { Blindness } \\ \text { Heart Attack } & \text { Hemiplegia } & \text { Paraplegia } \\ \text { Kidney Failure } & \text { Stroke } & \end{array}$

\section{Occupational HIV Insurance}

Tax Free Lump sum payment directly to the insured who are diagnosed with the Human Immunodeficiency Virus (H.I.V.) as a result of an occupational accident. Designed to provide the financial resources that will allow the insured to adjust to lifestyle changes that may occur after being diagnosed with HIV. Unlike life insurance, the benefit is payable to the insured - not the dependents. It's a living benefit. The benefit is tax-free. Unlike disability insurance, the benefit is not dependent on the member's ability or inability to work.

$\begin{array}{llll}\begin{array}{l}\text { Insurance Amount } \\ \$ 200,000\end{array} & \$ 50,000 & \$ 100,000 & \$ 150,000 \\ \begin{array}{l}\text { Monthly Premium } \\ \$ 24.80\end{array} & \$ 6.20 & \$ 12.40 & \$ 18.60\end{array}$

\section{Disability Insurance}

Your Board of Directors have negotiated a $10 \%$ discount with Canada Life, one of Canada's premier disability underwriters. They offer superior disability products including return of premium benefits that are second to none. As Emergency Physicians, the need for disability insurance is obvious. The Insurance consultants listed below can explain the benefits of this top line benefit to you.

\section{Health and Dental Flex Plan}

We have introduced 3 levels of health benefits as well as 3 levels of dental benefits. Each member will be able to decide what coverage is best for themselves and their families. The benefits start with very basic coverage and can be extended at your option.

EACH OF THE ABOVE 6 PLANS CAN BE APPLIED FOR SEPARATELY. ALL PLANS ARE AVAILABLE TO SPOUSES EXCEPT OCCUPATIONAL HIV INSURANCE.

For more information on these benefits please contact Mike Livie, RML Insurance Agencies Inc. tel (416) 694-1244 toll free 1-877-694-1244 Simon Jackson or Stephen Tung, Simon L. Jackson Insurance Brokers Ltd. tel (416) 495-7610, toll-free 1-800-247-1312,

Please visit our website at: http://www.sljacksonins.com/CAEP.htm

Insurance benefits provided by Seaboard/Northwest Life, Green Shield and Canada Life 